Received: 2 March 2018

Accepted: 7 June 2018

Published online: 23 July 2018

\section{Contribution of prostanoid FP receptor and prostaglandins in transient inflammatory ocular hypertension}

\author{
Reiko Yamagishi-Kimura, Megumi Honjo \& Makoto Aihara
}

We explored the involvement of FP receptor and endogenous prostaglandins (PGs) in transient ocular hypertension $(\mathrm{OH})$ induced by PGE2 or PGF2 $\alpha$ in mouse eyes. PGE2 and PGF2 $\alpha$ were topically applied to induce transient OH in Wild-type (WT) and FP-, EP1-, EP2-, and EP3-deficient (knockout [KO]) mice. To suppress endogenous PG production, the non-steroidal anti-inflammatory drug nepafenac was applied topically before treatment. PGE2 and PGF2 $\alpha$ induced significant $O H$ in the WT, FPKO, and EP1-3KO mice compared to the control $30 \mathrm{~min}$ after instillation, and the increase in IOP at 30 or $60 \mathrm{~min}$ after instillation in FPKO mice was significantly higher than that in the WT mice. The effects of PGF2 $\alpha$ on the increase in IOP were significantly weaker than those of PGE2, especially in EP1KO and EP3KO mice. Transient $\mathrm{OH}$ induced by PGE2 and PGF2 $\alpha$ was significantly attenuated by nepafenac treatment in FPKO mice. Transient OH was induced by PGE2 and PGF2 $\alpha$ in WT, FPKO, and EP1-3KO mice, which was enhanced in FPKO mice. This $\mathrm{OH}$ was significantly diminished by nepafenac treatment in FPKO mice, suggesting that FP receptor may have an important naïve physiological role in the eye, and could regulate IOP elevation during PG-associated ocular inflammation.

It has long been reported that inflammation-inducing substances, referred to as 'irins', are present in the eye, most of which have been clarified to be the prostaglandins (PGs) PGE2 and PGF2 $\alpha$. PGs have been recognized as predominantly inflammation-inducing substances or pro-inflammatory molecules in the eye. However, drugs and analogs related to PGs are currently the most commonly used agents to treat glaucoma and lower intraocular pressure (IOP), although their physiological roles in the eye have not been fully clarified.

Current PG-related drugs have high selectivity for the FP receptor. PGE2 has four distinct receptors, EP1, EP2, EP3, and EP4, of which PGF2 $\alpha$ binds to the FP receptor. Studies of drug receptor affinity and receptor-deficient (knockout $[\mathrm{KO}]$ ) mice have reported that the FP receptor has a crucial role in reducing $\mathrm{IOP}^{2-5}$. In addition, the EP3, EP2, and EP4 receptors are involved in lowering $\mathrm{IOP}^{6}$. Involvement of both the FP receptor and endogenous PGs has been reported not only in reductions of IOP, but also in maintenance of IOP homeostasis ${ }^{2,7-11}$.

However, the physiological role of the FP receptor in the eye has not been clarified, having thus far been evaluated only under conditions of reduced IOP using externally applied FP agonists. In our previous study, we speculated that IOP might differ between FPKO and wild-type (WT) mice; however, we found that the baseline IOPs during the day and at night did not differ significantly between FPKO and WT mice ${ }^{4}$. Therefore, we speculated that the FP receptor is unlikely to be involved in the maintenance of IOP under normal conditions, but rather may have an endogenous role in controlling IOP fluctuations in the case of ocular inflammation. In ocular inflammation, PGE2 and PGF2 $\alpha$ levels increase in the anterior chamber ${ }^{1}$. Clinically, fluctuations in IOP are often observed in uveitis. PGE2 and PGF2 $\alpha$ not only lower IOP, but have also been reported to increase IOP transiently in the early phase after instillation in mice ${ }^{6}$, monkeys ${ }^{12-14}$, rabbits $^{15}$, and humans ${ }^{16}$.

In this study, we investigated the involvement of the FP receptor and endogenous PGs in transient ocular hypertension $(\mathrm{OH})$ induced by PGE2 or PGF $2 \alpha$ in mouse eyes. 


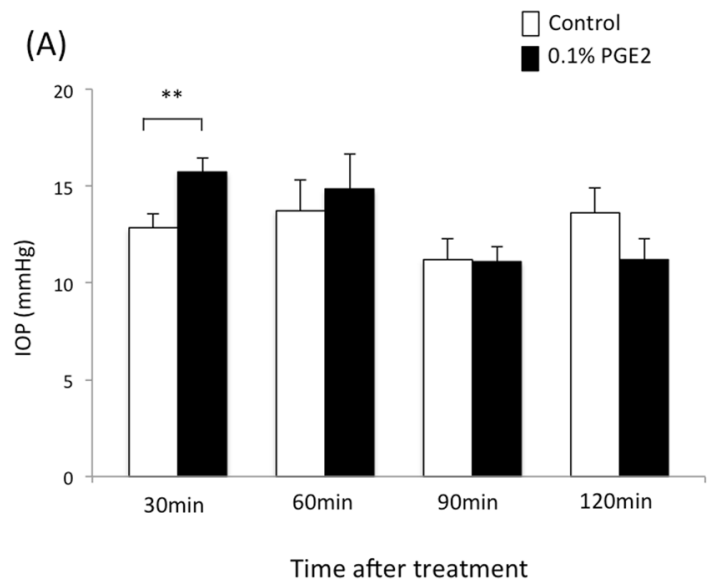

(B)

Figure 1. Time course of (A) intraocular pressure (IOP) change (mmHg) and (B) the IOP increase (\%) after treatment with $0.1 \%$ PGE2 in wild-type (WT) mice. Data are expressed as means \pm standard deviation (SD) $(\mathrm{n}=5-10) . * * \mathrm{p}<0.01$ for $0.1 \%$ PGE2-treated versus contralateral vehicle-treated eyes (control).

$$
\text { (A) }
$$

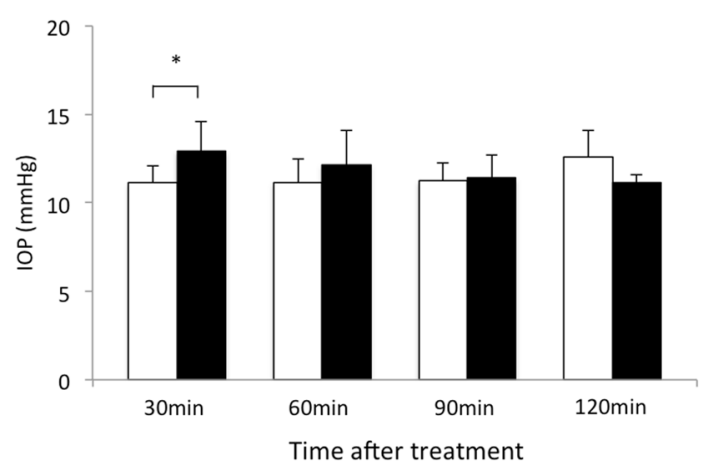

(B)

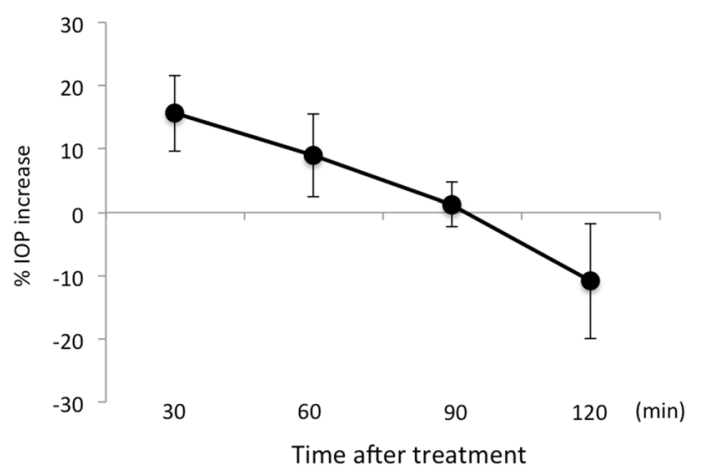

Figure 2. Time course of $(\mathbf{A})$ IOP change $(\mathrm{mmHg})$ and $(\mathbf{B})$ the IOP increase (\%) after treatment with $0.1 \%$ $\mathrm{PGF} 2 \alpha$ in WT mice. Data are expressed as means \pm SD $(n=5-9) . * p<0.05$ for the treated versus contralateral vehicle-treated eyes (control).

\section{Results}

Time-dependent IOP changes after treatment with PGE2 methyl ester in WT mice. For preliminary experiments, IOP was measured in WT mice using Tonolab at 0, 30, 60, 90 and 120 min after topical instillation of $0.01 \%$ or $0.1 \%$ PGE2 and PGF $2 \alpha$. There were significant differences by PGE2 and PGF2 $\alpha$ in lower concentration at $30 \mathrm{~min}$ after dosing compared to non-treated group. However, the IOP increase by $0.01 \%$ PGE2 or PGF $2 \alpha$ was minor compare to $0.1 \%$ of both drugs (Supplement Figure S1) Therefore, we determined the dose for PGE2 and PGF2 $\alpha$ as $0.1 \%$. Next, we measured IOP in WT mice 30, 60, 90 and 120 min after topical instillation of $0.1 \%$ PGE2 or PGF $2 \alpha(n=5-10$ at each time point). The IOP of each drug-treated group was compared to the vehicle control group using Student's t-test. The IOPs at $30 \mathrm{~min}$ after instillation of the vehicle or $0.1 \%$ PGE2 were $12.8 \pm 0.7$ and $15.7 \pm 0.7 \mathrm{mmHg}$, respectively, indicating that PGE2 significantly increased IOP compared to the control $30 \mathrm{~min}$ after instillation $(\mathrm{p}<0.001)$ in WT mice (Fig. 1). The IOPs at 60, 90 and $120 \mathrm{~min}$ after instillation of the vehicle and $0.1 \%$ PGE2 were $13.7 \pm 1.6$ and $14.8 \pm 1.8 \mathrm{mmHg}$ at $60 \mathrm{~min}, 11.2 \pm 1.1$ and $11.1 \pm 0.8 \mathrm{mmHg}$ at $90 \mathrm{~min}$, and $13.6 \pm 1.3$ and $11.2 \pm 1.1 \mathrm{mmHg}$ at $120 \mathrm{~min}$, respectively. At $120 \mathrm{~min}$ after dosing, $0.1 \%$ PGE2 lowered IOP, significantly $(\mathrm{p}<0.05)$. The IOP increase $(\%)$ between the PGE2-treated group and vehicle-treated control at 30,60, 90 and $120 \mathrm{~min}$ after instillation were $21.9 \pm 5.7,6.8 \pm 4.5,-0.9 \pm 3.0$ and $-17.6 \pm 7.1 \%$, respectively, indicating that the IOP increase decreased in a time-dependent manner.

Conversely, the IOPs at $30 \mathrm{~min}$ after instillation of the vehicle or $0.1 \%$ PGF2 $\alpha$ were $11.2 \pm 0.9$ and $12.9 \pm 1.7 \mathrm{mmHg}$, respectively, and $0.1 \%$ PGF2 $\alpha$ significantly increased the IOP at $30 \mathrm{~min}$ after instillation in WT mice $(\mathrm{p}=0.035)$ (Fig. 2). At 60, 90 and $120 \mathrm{~min}$ after instillation, the IOPs of vehicle-treated and PGF2 $\alpha$-treated eyes were $11.1 \pm 1.3$ and $12.2 \pm 1.9 \mathrm{mmHg}$ at $60 \mathrm{~min}, 11.2 \pm 1.0,11.4 \pm 1.3 \mathrm{mmHg}$ at $90 \mathrm{~min}$, and $12.6 \pm 1.5$ and $11.1 \pm 0.5 \mathrm{mmHg}$ at $120 \mathrm{~min}$; vehicle-treated and PGF2 $\alpha$-treated, respectively, and there were no significant differences in IOP between the PGF2 $\alpha$-treated group and vehicle-treated control. The IOP increase at 30, 60, 90 and 120 min after instillation were $15.6 \pm 6.0,8.9 \pm 6.6,1.2 \pm 3.5$ and $-10.8 \pm 9.1 \%$, respectively after PGF $2 \alpha$ 
(A)

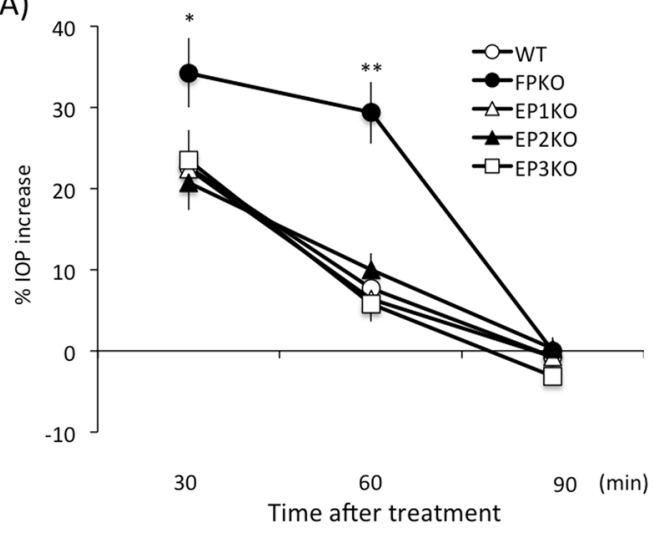

(B)

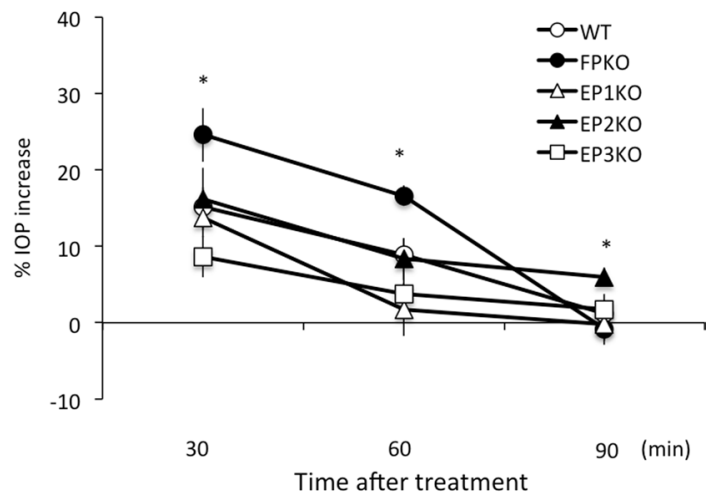

Figure 3. Time course of IOP increase with $0.1 \%$ (A) PGE2 and (B) PGF2 $\alpha$ in WT, FPKO, EP1KO, EP2KO, and EP3KO mice. Data are expressed as means $\pm S D(n=5-10)$. *** $\mathrm{p}<0.05$ or 0.01 for the WT versus KO mouse groups.

treatment, and these decreased in a time-dependent manner. The effect of PGF2 $\alpha$ on the IOP increase at $30 \mathrm{~min}$ after instillation was significantly weaker than that of PGE2 in WT mice $(\mathrm{p}=0.037)$.

Time-dependent IOP changes after 0.1\% PGE2 methyl ester treatment in FPKO, EP1-3KO, and WT mice. To explore the roles of the FP, EP1, EP2, and EP3 receptors in PGE2- and PGF2 $\alpha$ - induced OH, we measured the IOP of WT, FPKO, and EP1-3KO mice at 30, 60, and 90 min after topical instillation of $0.1 \%$ PGE2 or PGF2 $\alpha$ ( $n=5-10$ per time point). In preliminary experiment, there were no significant differences of IOP in all phenotype mice using microneedle methods (Supplementary Table S1). The IOP increase (\%) 30 and $60 \mathrm{~min}$ after instillation of 0.1\% PGE2 in WT, FPKO, and EP1-3KO mice were $22.7 \pm 5.4,34.2 \pm 12.9,22.3 \pm 6.3,20.7 \pm 8.7$, and $23.5 \pm 10.9 \%$ and $7.7 \pm 5.6,29.3 \pm 11.4,6.4 \pm 5.0,10.0 \pm 5.4,5.8 \pm 4.8 \%$, respectively (Fig. 3). Treatment with $0.1 \%$ PGE2 significantly increased the IOP at 30 and 60 min after instillation in FPKO mice compared to the $\mathrm{WT}(\mathrm{p}=0.030$ and 0.0003 , respectively). At $90 \mathrm{~min}$ after PGE2 treatment, there were no differences in the IOP increase between the WT mice and KO mice.

Meanwhile, the IOP increase at 30 and 60 min after treatment with $0.1 \%$ PGF2 $\alpha$ in WT, FPKO, and EP1$3 \mathrm{KO}$ mice were $15.1 \pm 8.6,24.6 \pm 11.1,13.8 \pm 6.7,16.2 \pm 10.8$, and $8.6 \pm 6.7 \%$ and $8.9 \pm 6.6,16.6 \pm 3.8,1.7 \pm 9.8$, $8.4 \pm 7.3$, and $3.8 \pm 8.0 \%$, respectively. Moreover, $0.1 \%$ PGF $2 \alpha$ significantly increased the IOP at 30 and $60 \mathrm{~min}$ after instillation in FPKO mice compared to the WT ( $p=0.045$ and 0.010 , respectively). There were no differences in the IOP increase between the WT and the other types of mice at 90 min after instillation of PGF2 $\alpha$. However, $0.1 \%$ PGF2 $\alpha$ significantly increased the IOP at $90 \mathrm{~min}$ after instillation in EP2KO mice compared to the WT $(\mathrm{p}=0.016)$ (Fig. 3B).

Both PGE2 and PGF2 $\alpha$ increased the IOP significantly in WT, FPKO, and EP1-3KO mice at 30 min after instillation; however, the influence of PGF2 $\alpha$ on the increase in IOP was significantly weaker than that of PGE2, especially in $\mathrm{EP} 1 \mathrm{KO}$ and $\mathrm{EP} 3 \mathrm{KO}$ mice $(\mathrm{p}=0.023$ and 0.0061 , respectively).

Involvement of endogenous PG production in transient OH by PGE2 and PGF2 $\alpha$. Transient $\mathrm{OH}$ may be derived from endogenously produced PGs. Therefore, we treated mouse eyes with the nonsteroidal anti-inflammatory drug (NSAID) nepafenac (0.1\%). After nepafenac treatment, IOP was measured in WT, FPKO, and EP1-3KO mice 60 min after topical instillation of 0.1\% PGE2 or PGF2 $\alpha$. As shown in Fig. 3, the IOP increase ratio was higher at $30 \mathrm{~min}$ after dosing than $60 \mathrm{~min}$, but the difference of IOP increase between WT mice and FPKO mice was more significant at $60 \mathrm{~min}$ after dosing than $30 \mathrm{~min}$. (p value of WT vs. FPKO was 0.03 and 0.0003 . at $30 \mathrm{~min}$ and $60 \mathrm{~min}$ after dosing, respectively). Therefore, we have selected a time point of $60 \mathrm{~min}$ after dosing in order to elucidate the influence of endogenous PGs. Treatment with nepafenac-only showed no effects on IOP in all phenotypes of mice (gray columns, Fig. 4A). After PGE2 treatment, the IOP increase with and without nepafenac treatment in WT mice were $7.5 \pm 5.3$ and $7.6 \pm 11.6 \%$, respectively. No significant effect of nepafenac on PGE2-induced OH was observed in WT mice. There were no significant differences in the IOP increase between non-treatment and nepafenac treatment in EP1-3KO mice (Fig. 4A). Conversely, the IOP increase in non-treated and nepafenac-treated FPKO mice were $27.9 \pm 11.6$ and $7.4 \pm 5.7 \%$, respectively, and PGE2-induced OH in FPKO mice was significantly attenuated by nepafenac treatment $(\mathrm{p}=0.00028)$ (Fig. 4A).

Likewise, under the $0.1 \%$ PGF2 $\alpha$ treatment, the IOP increase with and without $0.1 \%$ nepafenac treatment in WT mice were $8.9 \pm 6.6$ and $5.8 \pm 4.3 \%$, respectively, which did not differ significantly. Moreover, there were no significant differences in the IOP increase between non-treatment and nepafenac treatment in EP1-3KO mice (Fig. 4B). However, the IOP increase in the non-treated and nepafenac-treated FP mice were $17.7 \pm 2.4$ and $1.7 \pm 3.3 \%$, respectively, and PGF2 $\alpha$-induced $\mathrm{OH}$ was significantly diminished by nepafenac treatment in FPKO mice ( $\mathrm{p}=4.6 \mathrm{E}-6)$ (Fig. 4A). The difference between WT and FPKO in presence of PGF2 $\alpha$ and nepafenac was not statistically significant. $(\mathrm{p}=0.0702)$. 
(A)

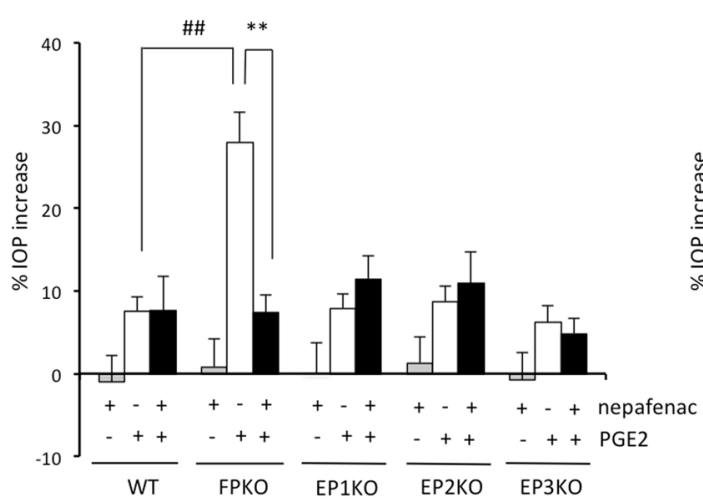

(B)

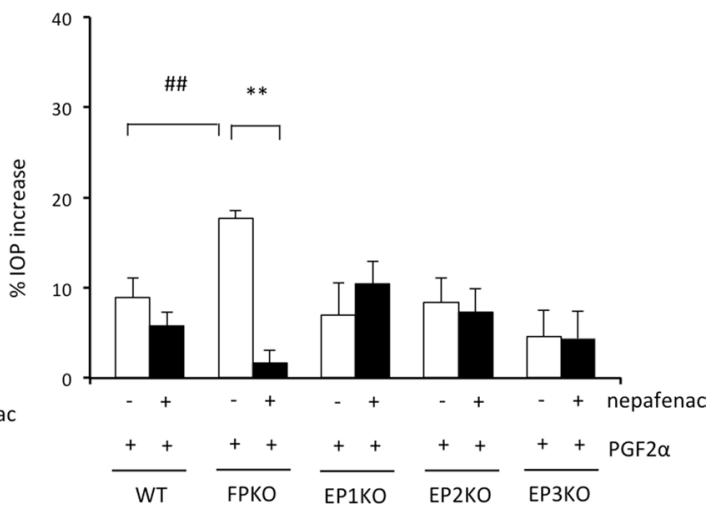

Figure 4. Influence of the nonsteroidal anti-inflammatory drug (NSAID) nepafenac on transient ocular hypertension (OH) induced by (A) PGE2 and (B) PGF2 $\alpha$ in WT, FPKO, EP1KO, EP2KO, and EP3KO mice. Data are expressed as the means \pm standard error of the mean $(n=6-8$ per column $) .{ }^{\# \#} \mathrm{p}<0.01$ for WT versus FPKO based on the Mann-Whitney U test. ${ }^{*} \mathrm{p}<0.01$ for NSAID (-) versus NSAID ( + ) based on the MannWhitney U test.

\section{Discussion}

We found that transient $\mathrm{OH}$ induced by PGE2 and PGF2 $\alpha$ in WT mice was enhanced in FPKO mice. This suggests that the FP receptor may have an important physiological role in stabilizing IOP fluctuations in PG-associated $\mathrm{OH}$. In general, the physiological role of the FP receptor has been implicated in uterine contractions and corpus luteum regression. Previously, there are many reports about IOP changes by PGE2 or PGF2 $\alpha$ instillation, but there were no reports to measure IOP in earlier phase in mice eyes like as our experiment. Our results show the fine and rapid changes of IOP occurring very early phase using microneedle methods. Moreover, there are no reports of the endogenous function of the FP receptor in the eye. Our understanding of the FP receptor is limited, being based only on its response to externally administrated agents (i.e., PG analogues) in glaucoma treatment. Thus, this is the first report to clarify a 'naïve' role of the FP receptor in the eye, which may act as a regulator of IOP elevation in cases of PG-associated ocular inflammation.

Several physiological challenges are known to increase IOP, such as surgical invasion and inflammation; however, the precise mechanisms involved in $\mathrm{OH}$ are not well understood ${ }^{17-25}$. PGE2 is known to be released under such conditions. Similarly, in this study, topical instillation of PGE2 resulted in transient OH (Figs 1, 3, and 4); therefore, we speculate that PGE2 may be a major contributor to $\mathrm{OH}$ in ocular inflammation. However, our study suggested that the EP1, EP2, and EP3 receptors were not directly related to this mechanism, because there were no significant changes in IOP fluctuation in the respective KO mice (Fig. 3A). Previously, PGE2-induced transient $\mathrm{OH}$ was attenuated by dipyridamole, which inhibited cAMP-phosphodiesterase and cAMP production $^{26}$. Thus, PGE2-induced transient $\mathrm{OH}$ may partially act via an increase in cAMP after the activation of the G protein-coupled receptors EP2 and EP4, although it is unknown whether this pathway is directly or indirectly activated through other molecules. Unfortunately, the role of EP4 was not clarified in our study, because EP4 deficiency is embryonically lethal in mice. Therefore, EP4 may have an important role in increased IOP. Future studies should include conditional $\mathrm{KO}$, multiple $\mathrm{KO}$ mice, or antagonists for each receptor to clarify the underlying mechanism of $\mathrm{OH}$.

Similar to PGE2, transient OH was observed after PGF2 $\alpha$ administration in this study, but the response was weaker than that for PGE2. The current preferred glaucoma drugs, PG analogues, are PGF2 $\alpha$ derivatives developed with the aim of increasing affinity for the FP receptor; however, PGF2 $\alpha$ also has an affinity for EP receptors $^{27}$. Therefore, we speculate that the IOP increase by PGE2 or PGF2 $\alpha$ was mediated by nonspecific activity of PGE2 or PGF2 $\alpha$, considering a previous report that PGF2 $\alpha$ affect not only FP receptors but also other prostanoid receptors $^{27}$. In our previous mouse study, current PG analogues caused a significant IOP reduction without $\mathrm{OH}$ in the early phase $\mathrm{e}^{28}$. Taken together, partial activation of EP receptors may contribute to the transient $\mathrm{OH}$ induced by PGF $2 \alpha$. Thus, our results indicate that the mechanisms of induction of transient OH are similar for both PGE2 and PGF $2 \alpha$, being mediated by EP receptors.

The FP receptor has an important role in suppressing PGE2-induced transient $\mathrm{OH}$. Moreover, transient $\mathrm{OH}$ induced by PGE2 and PGF2 $\alpha$ was significantly attenuated by NSAID treatment in FPKO mice in this study, but not in the other KO or WT mice (Fig. 4). This indicated that endogenous PGF2 $\alpha$ was produced after PGE2 or PGF2 $\alpha$ stimulation. It has been previously reported that cyclooxygenase (COX) activity is induced by FP receptor stimulation ${ }^{29}$. These results suggest that, in ocular inflammation, the levels of various PGs, acting as local mediators, increase via COX activation and subsequently produced enzymes, and that PGE2 acts on EP receptors, ultimately leading to an increase in IOP via cAMP augmentation or other unknown mechanisms. Simultaneously, enhanced PGF $2 \alpha$ also stimulates FP receptors, leading to a reduction in IOP. Further, it is possible that non-PG molecules (e.g. thromboxanes or other downstream molecules of the COX-2 pathway) involved in the IOP increase since the NSAID abrogates the IOP increase even in the presence of PG treatment. This actually indicates that PG treatment might be inducing other IOP elevating factors, however, it was not easy to prove this in 
PGE2

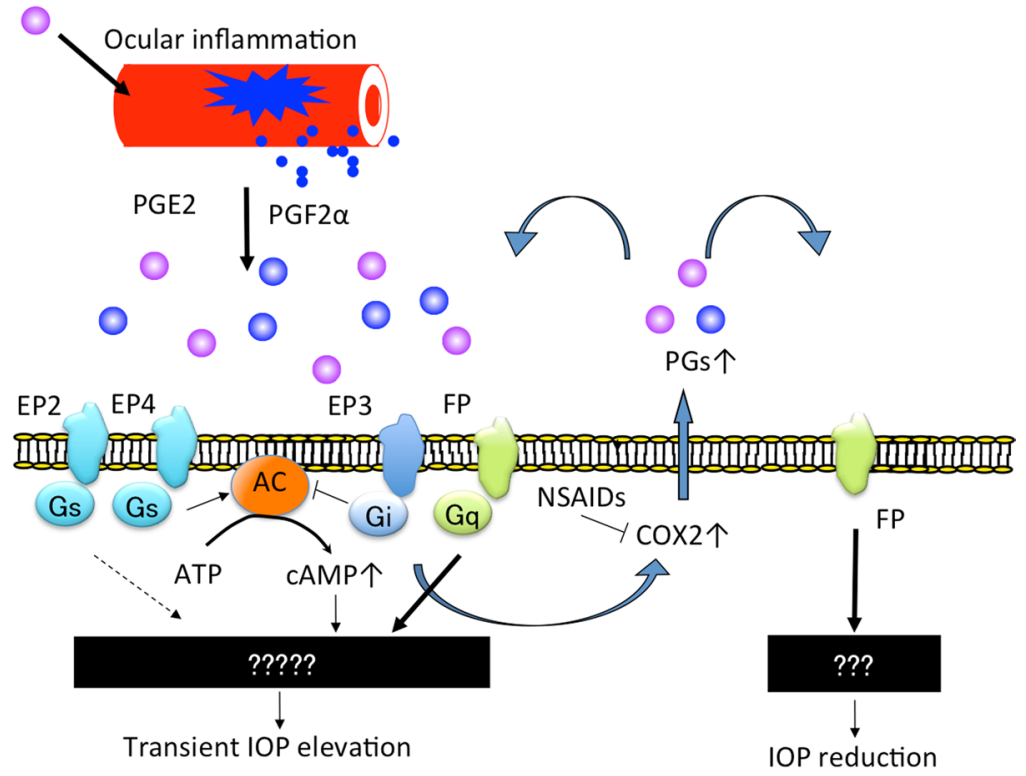

Figure 5. Involvement of PGE2, PGF2 $\alpha$ and FP receptors in regulation of IOP.

the present study because there are various factors involved in the maintenance of IOP. However, at least in the present study, it was clarified that the cox-activity induced by the stimulation of FP receptors or other receptors was involved in homeostasis maintenance of IOP when IOP was elevated by certain stimuli. These mechanisms are summarized in a schematic diagram of our hypothesis (Fig. 5). If the FP receptor does not sufficiently respond to inflammation, the eye may be exposed to high pressure, inducing optic disc damage or decreased ocular blood flow. However, this speculation is based only on the effects of NSAID treatment and prostanoid receptor deficiencies on PG-induced OH, and further studies are needed to clarify the action of PGs in the aqueous fluid.

Several limitations of the present study must be addressed. First, we measured IOP invasively using the microneedle method; therefore, we could not measure or compare IOP, within the same eye, at baseline and each subsequent time point. Ideally, we should have measured IOP using a non-invasive device, such as the Icare $^{\circledR}$ Tonolab (Icare Finland Oy, Vantaa, Finland), in a time-dependent manner after instillation. However, the accuracy of the Tonolab was too low to evaluate transient OH induced by PGE2 and PGF2 $\alpha$; therefore, we used the microneedle method. It is necessary to improve the accuracy of tonometric measurements of IOP in mice for future studies. Second, we used concentrations of PGE2 and PGF2 $\alpha$ of $0.1 \%$, based on the results of preliminary experiments in which elevated IOP was confirmed by topical instillation. However, the actual drug concentration in the eye was unknown, and it was unclear whether it clinically reflected the concentration of PGs that may occur in the eye during inflammation. In the present study, we could not measure the PG concentration in the eye using mass spectrometry due to the low volume of aqueous humor in mouse eyes. Therefore, future studies should aim to increase the sensitivity of such measurements and determine the PG concentration in the eye. Finally, our results have not completely elucidated the role of FP receptors in the present study, although we speculate that FP receptors may act to lower IOP when ocular hypertension is induced by certain stimulus. We may get more new knowledge when we could do further experiments using antagonists of these receptors. However, unfortunately at present, as far as we know, there are no suitable antagonists for these receptors having high selectivity, and there are no evidences that these antagonists act topically. We would like to consider these experiments using antagonist as an important task in the future.

In conclusion, we clarified that PGE2 and PGF2 $\alpha$ induced transient $\mathrm{OH}$ in mouse eyes through secondary induction of endogenous PGs, and this transient $\mathrm{OH}$ was suppressed by FP receptor stimulation, a mechanism that is often exploited to lower IOP via external administration of PG analogues. Although elucidating the mechanism underlying IOP fluctuation adjustment and control in the eye, in the case of disease, inflammation, or even normal status, remains a challenge, we showed that the FP receptor might have a biological role in lowering or adjusting IOP against endogenous PG production in vivo. Elucidating the factors controlling the IOP could lead to the establishment of a new treatment for glaucoma.

\section{Materials and Methods}

Materials. We used PGE2 methyl ester (Cayman Chemical, Ann Arbor, MI, USA), PGF2 $\alpha$ methyl ester, and nepafenac (Nevanac ${ }^{\circledR}$ ophthalmic solution $0.1 \%$; donated by Alcon Pharma, Tokyo, Japan) as the NSAID solution in this study.

Animals. All animals used in this study were treated in accordance with the Association for Research in Vision and Ophthalmology Statement for the Use of Animals in Ophthalmic and Vision Research, as well as the rules outlined by the local Animal Use Committee of the University of Tokyo. The Ethics Committee for Animal Experiments at University of Tokyo approved all experimental procedures. As WT mice, male C57BL/6 J mice 
were purchased from Japan Tokyo Laboratory Animals Science Co. Ltd. (Tokyo, Japan). FPKO, EP1KO, EP2KO, and EP3KO mice ${ }^{30,31}$ were donated by the Department of Drug Discovery Medicine, Kyoto University Graduate School of Medicine (Kyoto, Japan). Mice were bred and housed in clear cages loosely covered with air filters. The cages contained white chip bedding. The temperature was maintained at $21^{\circ} \mathrm{C}$ under a 12:12-h light:dark cycle. All mice had access to food and water ad libitum. We used mice older than 8 weeks of age.

Preparation and instillation of ophthalmic solutions. PGE2 methyl ester and PGF2 $\alpha$ methyl ester were stored at $-80^{\circ} \mathrm{C}$ in $100 \%$ dimethyl sulfoxide (DMSO) and were diluted with phosphate-buffered saline immediately before use to yield a 5\% DMSO concentration. We used the ester form of PGs as eye drops because this chemical structure readily penetrates into the anterior chamber under a low concentration of drug. With a micropipette, $3 \mu \mathrm{L}$ of each drug solution was topically applied in a masked manner to one eye selected at random, and the other eye was used as a vehicle-treated control.

Mouse IOP measurement. We used two instruments to measure IOP; the microneedle method and he rebound tonometer (TonoLab; Icare ${ }^{\circledR}$, Vantaa, Finland). IOP was measured directly by the microneedle method in anesthetized mice as previously described ${ }^{32}$. Briefly, a microneedle made of borosilicate glass $(75-100 \mu \mathrm{m}$ in tip diameter, $1.0 \mathrm{~mm}$ in outer diameter; World Precision Instruments, Sarasota, FL, USA) was connected to a pressure transducer (model BLPR; World Precision Instruments). The pressure detected by the transducer was recorded with a data acquisition and analysis system (PowerLab; ADInstruments, Colorado Springs, CO, USA). The microneedle was placed in the anterior chamber, and the pressures in both eyes were recorded in mice under ketamine/xylazine anesthesia. With the TonoLab, automatically averaged readings were recorded. The IOP was measured in conscious mice. All measurements were performed from 21:00-23:00.

We randomly applied $3 \mu \mathrm{L}$ of saline, $0.1 \%$ PGE2 methyl ester (PGE2), and $0.1 \%$ PGF2 $\alpha$ methyl ester (PGF2 $\alpha$ ) to one eye of each mouse ( $n=7-10$ per group). The vehicle-treated contralateral eye served as a control. The effect of each drug was calculated as $100 \times$ (IOP of treated eye - IOP of contralateral eye)/IOP of contralateral eye (\%) in each mouse, referred to as the IOP increase. In another series of experiments, the NSAID nepafenac (Nevanac ${ }^{\circledR}$ ophthalmic solution $0.1 \%$ ) was topically administered to each mouse in both eyes 30 min before the topical administration of PGE2 or PGF2 $\alpha$ to suppress endogenous PG production, and the IOP was measured $1 \mathrm{~h}$ after administration of PGE2 or PGF2 $\alpha$.

Data and statistical analysis. All results are presented as the means \pm standard deviation (SD). Statistical analyses were performed using JMP Pro 11 software (SAS Institute Inc., Cary, NC, USA). Student's $t$-test with the post-hoc Bonferroni test was used for between-group comparisons. Dunnett's multiple comparison test was employed to compare more than two groups. All data represent the means of at least three independent experiments. Differences were considered to be statistically significant when $\mathrm{p}<0.05$.

\section{References}

1. Anggard, E. \& Samuelsson, B. Smooth muscle stimulationg lipids in sheep iris. The identification of prostaglandin F2a. Prostaglandins and related factors 21. Biochem Pharmacol 13, 281-283 (1964).

2. Ota, T., Aihara, M., Saeki, T., Narumiya, S. \& Araie, M. The IOP-lowering effects and mechanism of action of tafluprost in prostanoid receptor-deficient mice. Br J Ophthalmol 91, 673-676 (2007).

3. Crowston, J. G. et al. Effect of bimatoprost on intraocular pressure in prostaglandin FP receptor knockout mice. Invest Ophthalmol Vis Sci 46, 4571-4577 (2005).

4. Ota, T., Aihara, M., Narumiya, S. \& Araie, M. The effects of prostaglandin analogues on IOP in prostanoid FP-receptor-deficient mice. Invest Ophthalmol Vis Sci 46, 4159-4163 (2005).

5. Crowston, J. G., Lindsey, J. D., Aihara, M. \& Weinreb, R. N. Effect of latanoprost on intraocular pressure in mice lacking the prostaglandin FP receptor. Invest Ophthalmol Vis Sci 45, 3555-3559 (2004).

6. Saeki, T., Ota, T., Aihara, M. \& Araie, M. Effects of prostanoid EP agonists on mouse intraocular pressure. Invest Ophthalmol Vis Sci 50, 2201-2208 (2009).

7. Camras, C. B. \& Podos, S. M. The role of endogenous prostaglandins in clinically-used and investigational glaucoma therapy. Prog Clin Biol Res 312, 459-475 (1989).

8. Turan-Vural, E., Torun-Acar, B. \& Acar, S. Effect of ketorolac add-on treatment on intra-ocular pressure in glaucoma patients receiving prostaglandin analogues. Ophthalmologica 227, 205-209 (2012).

9. Yousufzai, S. Y., Ye, Z. \& Abdel-Latif, A. A. Prostaglandin F2 alpha and its analogs induce release of endogenous prostaglandins in iris and ciliary muscles isolated from cat and other mammalian species. Exp Eye Res 63, 305-310 (1996).

10. Chiba, T., Kashiwagi, K., Chiba, N. \& Tsukahara, S. Effect of non-steroidal anti-inflammatory ophthalmic solution on intraocular pressure reduction by latanoprost in patients with primary open angle glaucoma or ocular hypertension. Br J Ophthalmol 90, 314-317 (2006).

11. Kashiwagi, K. \& Tsukahara, S. Effect of non-steroidal anti-inflammatory ophthalmic solution on intraocular pressure reduction by latanoprost. Br J Ophthalmol 87, 297-301 (2003).

12. Crawford, K. S. \& Kaufman, P. L. Dose-related effects of prostaglandin F2 alpha isopropylester on intraocular pressure, refraction, and pupil diameter in monkeys. Invest Ophthalmol Vis Sci 32, 510-519 (1991)

13. Nilsson, S. F., Samuelsson, M., Bill, A. \& Stjernschantz, J. Increased uveoscleral outflow as a possible mechanism of ocular hypotension caused by prostaglandin F2 alpha-1-isopropylester in the cynomolgus monkey. Exp Eye Res 48, 707-716 (1989).

14. Gabelt, B. T. \& Kaufman, P. L. Prostaglandin F2 alpha increases uveoscleral outflow in the cynomolgus monkey. Exp Eye Res 49, 389-402 (1989)

15. Camras, C. B., Bito, L. Z. \& Eakins, K. E. Reduction of intraocular pressure by prostaglandins applied topically to the eyes of conscious rabbits. Invest Ophthalmol Vis Sci 16, 1125-1134 (1977).

16. Villumsen, J. \& Alm, A. Prostaglandin F2 alpha-isopropylester eye drops: effects in normal human eyes. Br J Ophthalmol 73, 419-426 (1989).

17. Acar, U. et al. Posttraumatic intraocular pressure elevation and associated factors in patients with zone I open globe injuries. Ulus Travma Acil Cerrahi Derg 19, 115-118 (2013).

18. Mao, Z., Chen, X. B., Zhong, Y. M., Guo, X. X. \& Liu, X. Damage to the Blood-Aqueous Barrier in Ocular Blunt Trauma and Its Association with Intraocular Pressure Elevation. Ophthalmic Res 56, 92-97 (2016). 
19. Paterson, C. A., Eakins, K. E., Paterson, E., Jenkins, R. M. \& Ishikawa, R. The ocular hypertensive response following experimental acid burns in the rabbit eye. Invest Ophthalmol Vis Sci 18, 67-74 (1979).

20. Perkins, E. S. Prostaglandins and ocular trauma. Adv Ophthalmol 34, 149-152 (1977).

21. Hayashi, K., Yoshida, M., Manabe, S. I. \& Yoshimura, K. Prophylactic Effect of oral acetazolamide against intraocular pressure elevation after cataract surgery in eyes with glaucoma. Ophthalmology 124, 701-708 (2017).

22. $\mathrm{Lu}$, J. et al. Comparison of topically applied flurbiprofen or bromfenac ophthalmic solution on post-operative ocular hypertension in canine patients following cataract surgery. Vet Ophthalmol 20, 107-113 (2017).

23. Matusow, R. B., Herring, I. P., Pickett, J. P., Henao-Guerrero, N. \& Werre, S. R. Effects of perioperative topical dorzolamide hydrochloride-timolol maleate administration on incidence and severity of postoperative ocular hypertension in dogs undergoing cataract extraction by phacoemulsification. J Am Vet Med Assoc 249, 1040-1052 (2016).

24. Slabaugh, M. A., Bojikian, K. D., Moore, D. B. \& Chen, P. P. Risk factors for acute postoperative intraocular pressure elevation after phacoemulsification in glaucoma patients. J Cataract Refract Surg 40, 538-544 (2014).

25. Melancia, D., Abegão Pinto, L. \& Marques-Neves, C. Cataract surgery and intraocular pressure. Ophthalmic Res 53, 141-148 (2015).

26. Podos, S. M. Effect of dipyridamole on prostaglandin-induced ocular hypertension in rabbits. Invest Ophthalmol Vis Sci 18, 646-648 (1979).

27. Sharif, N. A., Kelly, C. R., Crider, J. Y., Williams, G. W. \& Xu, S. X. Ocular hypotensive FP prostaglandin (PG) analogs: PG receptor subtype binding affinities and selectivities, and agonist potencies at FP and other PG receptors in cultured cells. J Ocul Pharmacol Ther 19, 501-515 (2003).

28. Ota, T., Murata, H., Sugimoto, E., Aihara, M. \& Araie, M. Prostaglandin analogues and mouse intraocular pressure: effects of tafluprost, latanoprost, travoprost, and unoprostone, considering 24-hour variation. Invest Ophthalmol Vis Sci 46, 2006-2011 (2005).

29. Tsuboi, $\mathrm{K}$. et al. Uterine expression of prostaglandin $\mathrm{H} 2$ synthase in late pregnancy and during parturition in prostaglandin $\mathrm{F}$ receptor-deficient mice. Endocrinology 141, 315-324 (2000).

30. Ushikubi, F. et al. Impaired febrile response in mice lacking the prostaglandin E receptor subtype EP3. Nature 395, 281-284 (1998).

31. Sugimoto, Y. et al. Failure of parturition in mice lacking the prostaglandin F receptor. Science 277, 681-683 (1997).

32. Aihara, M., Lindsey, J. D. \& Weinreb, R. N. Reduction of intraocular pressure in mouse eyes treated with latanoprost. Invest Ophthalmol Vis Sci 43, 146-150 (2002).

\section{Acknowledgements}

The English in this document has been checked by at least two professional editors, both native speakers of English. For a certificate, please see: http://www.textcheck.com/certificate/MLz6SY.

\section{Author Contributions}

R.Y., M.H. and M.A. conceived the experiments, R.Y. conducted the experiments. All authors reviewed the manuscript.

\section{Additional Information}

Supplementary information accompanies this paper at https://doi.org/10.1038/s41598-018-29273-1.

Competing Interests: The authors declare no competing interests.

Publisher's note: Springer Nature remains neutral with regard to jurisdictional claims in published maps and institutional affiliations.

Open Access This article is licensed under a Creative Commons Attribution 4.0 International

License, which permits use, sharing, adaptation, distribution and reproduction in any medium or format, as long as you give appropriate credit to the original author(s) and the source, provide a link to the Creative Commons license, and indicate if changes were made. The images or other third party material in this article are included in the article's Creative Commons license, unless indicated otherwise in a credit line to the material. If material is not included in the article's Creative Commons license and your intended use is not permitted by statutory regulation or exceeds the permitted use, you will need to obtain permission directly from the copyright holder. To view a copy of this license, visit http://creativecommons.org/licenses/by/4.0/.

(c) The Author(s) 2018 